\title{
Effect of Transient Heat Transfer of a Condenser on a Cascade Heat Pump Performance
}

\author{
Piman Nenkaew and Chittin Tangthieng* \\ Department of Mechanical Engineering, Faculty of Engineering, Chulalongkorn University, Bangkok, \\ Thailand \\ *E-mail: qed690@yahoo.com
}

\begin{abstract}
Transient heat transfer of a condenser and its effect on a cascade heat pump performance are investigated by comparing experimental results with the prediction from a mathematical model. In the experiment part, the cascade heat pump consists of the lowtemperature refrigeration cycle using R22 and the high-temperature heat pump cycle using $\mathrm{R} 134 \mathrm{a}$. The transient effect is presented by circulating water to receive the rejection heat from the condensing refrigerant of the cascade heat pump causing the rise of the hot water temperature. On the other hand, a mathematic model of the condensation heat consisting of the heat transfer models in the two-phase mixture and the superheated vapor regions is developed. The effect of the hot water flow rate on the hot water temperature and the condensation heat is examined. The result indicates that the hot water temperature continuously increases with time. The condensation heat rapidly increases at the beginning and gradually increases with time. The agreement between the results obtained from the experiment and the model prediction is obtained. The result from the model prediction indicates that the heat transfer on the R134a side dominates the total heat transfer mechanism. The experimental result shows that the COP of the heat pump increases with increasing hot water flow rate, leading to the higher efficiency of the heat pump.
\end{abstract}

Keywords: Transient heat transfer, condenser, cascade heat pump, hot water.

ENGINEERING JOURNAL Volume 20 Issue 3

Received 10 September 2015

Accepted 5 January 2016

Published 19 August 2016

Online at http://www.engj.org/

DOI:10.4186/ej.2016.20.3.49 


\section{Introduction}

A cascade heat pump is a refrigeration cycle configuration which be used in a specific application like a large temperature lift between heat source and heat sink [1]. The aim of the cascade system is to increase the system efficiency. The cascade heat pump consists of two refrigeration cycles, the low-temperature refrigeration cycle and the high-temperature heat pump cycle. The refrigeration cycle absorbs heat from a cooling medium and transfers the heat to the heat pump cycle via a cascade heat exchanger. Thereafter, the heat pump cycle rejects the heat to a warmer medium. The heat transfer characteristics of the cascade heat pump have been performed by many researches. Bhattacharyya et al. [1-2] experimentally analyzed performance of a cascade refrigeration system with natural refrigerants. It concluded that the performance of the system was highly dependent on the evaporating temperature of the low temperature cycle, the condensing temperature of the high temperature cycle and the temperature difference between the condensing temperature of the low temperature cycle and the evaporating temperature of the high temperature cycle. Dopazo et al. [3] theoretical analyzed a cascade refrigeration system for cooling applications at the very low temperature source. The results showed that the use of both the energy and exergy method could obtain the optimization of the condensing temperature of the low temperature cycle and the evaporating temperature of the high temperature cycle.

A cascade heat pump can be applied in an application, which requires both heating and cooling effects. Colorado et al. [4], Kim et al. [5] experimentally and numerically studied an air to water cascade heat pump with various refrigerants. The system simultaneously supplied both the cooling air and the hot water. Optimized refrigerant temperatures predicted by numerical method were compared to the experimental results. Jung et al. [6], Lee et al. [7], Park et al. [8] experimentally analyzed hot water making from both a heat pump and a cascade heat pump. Hot water temperature obtained from the cascade system was higher than that in case of the single one.

The researches related to the heat transfer in the heat-exchanging device in the refrigerating system have been extensively studied. Jokar et al. [9] experimentally analysed heat transfer of an evaporator and a condenser of a refrigeration cycle. The result showed that the single phase heat transfer coefficient correlation for macro channel plate heat exchanger could not apply with the two-phase mixture state. Longo A. G. [10] experimentally and numerically analysed the effect of the refrigerant mass flux, and the saturated temperature on R134a condensation heat transfer. The heat transfer coefficient of R134a was compared between the experimental results and the analytical results. In the two-phase mixture region, the heat transfer coefficient was derived by Nusselt and Akers relations [11,12]. In the superheated region, the heat transfer coefficient was derived by Webb relation [13]. In the extension of the previous work, the effect of the superheated vapor on heat transfer inside a brazed plate heat exchanger is experimentally investigated [14]. The heat transfer coefficient of the superheated region was higher 5-10\% than that in case of the saturation region under the same refrigerant mass flux. But there was no effect on the pressure drop.

Mancin et al. [15] experimentally investigated condensation heat transfer coefficient of $15 \mathrm{~K}$ superheated vapor of R407c and R410a inside a brazed plate heat exchanger. The refrigerant mass flux and the wall-saturation temperature difference were varied. At the low refrigerant mass flux, the heat transfer coefficient did not depend on the mass flux. But the heat transfer coefficient increased with the refrigerant mass flux which was higher than $40 \mathrm{~kg} / \mathrm{m}^{2} \mathrm{~s}$. And the heat transfer coefficient decreased with the increase of the wall-saturation temperature difference. The theoretical and numerical analysis of the characteristics and heat transfer of the two-phase flow of a plate heat exchanger is performed by Grabenstien et al. [16].

Yang et al. [17] experimentally investigated the effect of the flow direction on the heat transfer coefficient of R410a evaporated of a plate heat exchanger. The evaporation heat transfer coefficient in case of the parallel flow was higher than that in case of the counter flow at the constant superheated value.

Because many cascade heat pumps operate under the transient condition, it would be beneficial to investigate how the produced hot water from the heat pump will affect the performance of the heat pump itself. The objective of this paper is to study the effect of transient heat transfer of a condenser on a cascade heat pump performance. The model focusing on the heat transfer mechanism in the condenser is developed to verify the hot water temperature at the outlet of the condenser and the condensation heat obtained from experimental results. The investigation of the heat transfer characteristics of the condenser by using the developed model is made. The effects of the transient behavior of the hot water flow rate on the compressor power and the COP of the heat pump are presented. 


\section{Experimental Setup}

\subsection{A Cascade Heat Pump}

Figure 1 shows the experimental setup of a cascade heat pump. The system consists of 4 systems: the chilled water system, the low-temperature refrigeration cycle using R22, the high-temperature heat pump cycle using R134a and the hot water system. The chilled water system supplies heat to the evaporator of the refrigeration cycle with the maximum cooling load of $8.45 \mathrm{KW}$. The heat is transferred to the heat pump cycle through the cascade heat exchanger. Hot water is pumped from the storage tank to take the rejection heat at the condenser and recirculates back to the tank. The condenser of the cascade heat pump is a brazed plate heat exchanger, of which the geometrical characteristics are shown in Table 1.

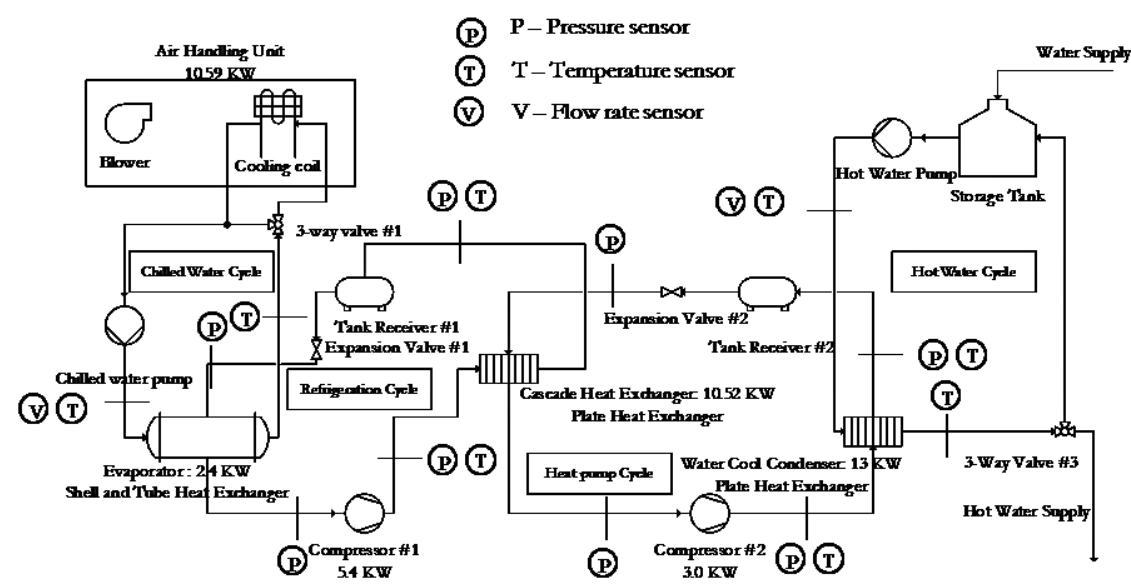

Fig. 1. The experimental setup of the cascade heat pump.

Table 1. Geometrical characteristic of a plate in the brazed plate heat exchanger.

\begin{tabular}{cc}
\hline Geometrical characteristic & Value \\
\hline Fluid flow plate length, $\mathrm{L}(\mathrm{mm})$ & 466 \\
Area of the plate $\left(\mathrm{m}^{2}\right)$ & 1.235 \\
Enlargement factor $\Phi$ & 0.96 \\
Plate wall thickness, $\mathrm{s}(\mathrm{mm})$ & 9.2 \\
Distance between 2 plates, $\mathrm{t}(\mathrm{mm})$ & 1.9232 \\
Number of plates & 28 \\
Number of channels on refrigerant side, $\mathrm{n}_{\mathrm{ch}, \mathrm{r}}$ & 14 \\
Number of channels on water side, $\mathrm{n}_{\mathrm{ch}, \mathrm{w}}$ & 13 \\
\hline
\end{tabular}

\subsection{Experimental Procedure}

In the experiment, the hot water temperature, the refrigerant temperature and pressure are measured at the location as shown in Fig. 1. The turbine flowmeter is used to measure the hot water flow rate. The water temperature is measured by PT-100 RTD. The refrigerant temperature is measured by type-K thermocouple. The refrigerant pressure is measured by a pressure transducer. The compressor power is measured by power meter. All measuring data are recorded in a personal computer using the data logger. The accuracies of all measuring devices are shown in Table 2. After the hot water flow rate and the hot water temperatures at the condenser are obtained, the condensation heat can be determined by Eq. (1).

$$
\dot{Q}_{H P}=\dot{m}_{w} c_{p, w}\left(T_{w, o}-T_{w, i}\right)
$$


Table 2. The accuracy of Experimental instrument

\begin{tabular}{ccl}
\hline Parameter & Experimental instrument & Accuracy \\
\hline Water temperature & Thermocouple Type K & $\pm 0.5^{\circ} \mathrm{C}$ \\
Ambient and refrigerant & RTD PT100 & $\pm 0.3^{\circ} \mathrm{C}$ \\
temperature & Turbine flowmeter & $\pm 2 \%$ \\
Hot water flowmeter & Pressure transducer & $\pm 0.5 \%$ \\
Refrigerant pressure & Power meter & $\pm 0.5 \%$ \\
Compressor power & Data logger & $\pm 0.1 \%$ \\
\hline
\end{tabular}

In this experiment, the hot water flow rate varies from 6,12 to 16 litre/min whereas the cooling load in the refrigeration cycle remains constant at $8.0 \mathrm{~kW}$. The duration of the experimental period is different based on the different hot water flow rates because the operation of the experimental rig will be terminated when the condensing pressures of the heat pump cycle reach 22 barg. As a result, the duration of the experimental period in case of the low hot water flow rate will be shorter than that in case of the high hot water flow rate. All experimental data are recorded by the data logger in every three seconds.

\section{Mathematical Model}

Heat transfer of the condenser of the cascade heat pump is predicted by a mathematic model to compare with the experimental result. The model has assumptions as follows:

1) R134a is saturated liquid at the outlet of the condenser.

2) The input parameters for the model are the refrigerant temperature at the inlet of the condenser, the refrigerant condensing temperature and the hot water temperature at the inlet of the condenser.

3) The thermal resistance from heat conduction through the plate material is neglected.

4) The pressure drop effect within the heat exchanger is neglected.

The temperature profiles of R134a and water of the condenser is depicted in Fig. 2. The heat transfer of the condenser is divided into 2 sections: the two phase mixture region and the superheated vapor region.

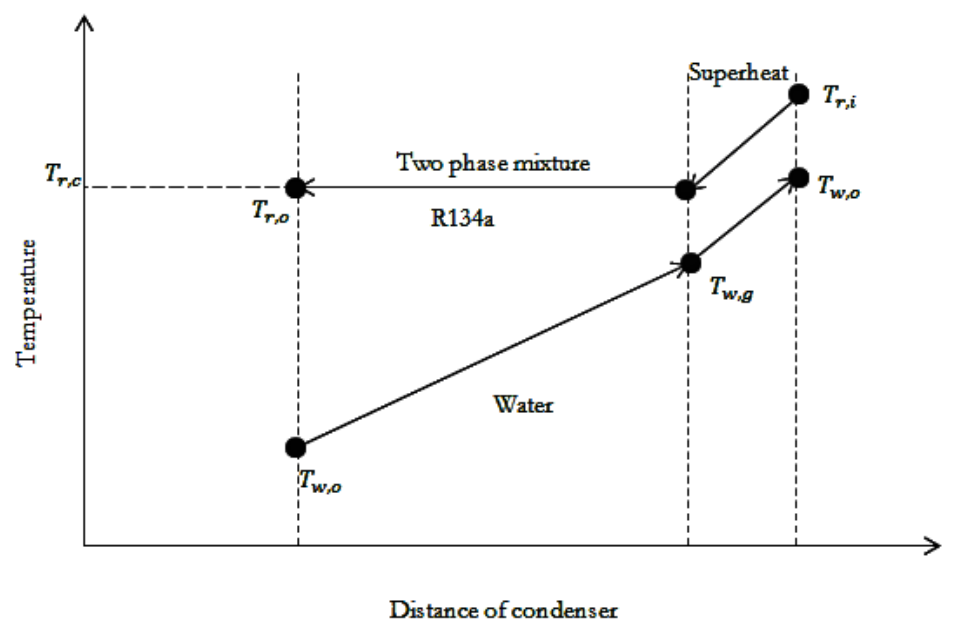

Fig. 2. Temperature profiles of a condenser.

The calculation procedure of the prediction of the hot water temperature at the outlet of the condenser or $\mathrm{T}_{\mathrm{w}, \mathrm{o}}$ in Fig. 2 is depicted in Fig. 3. 


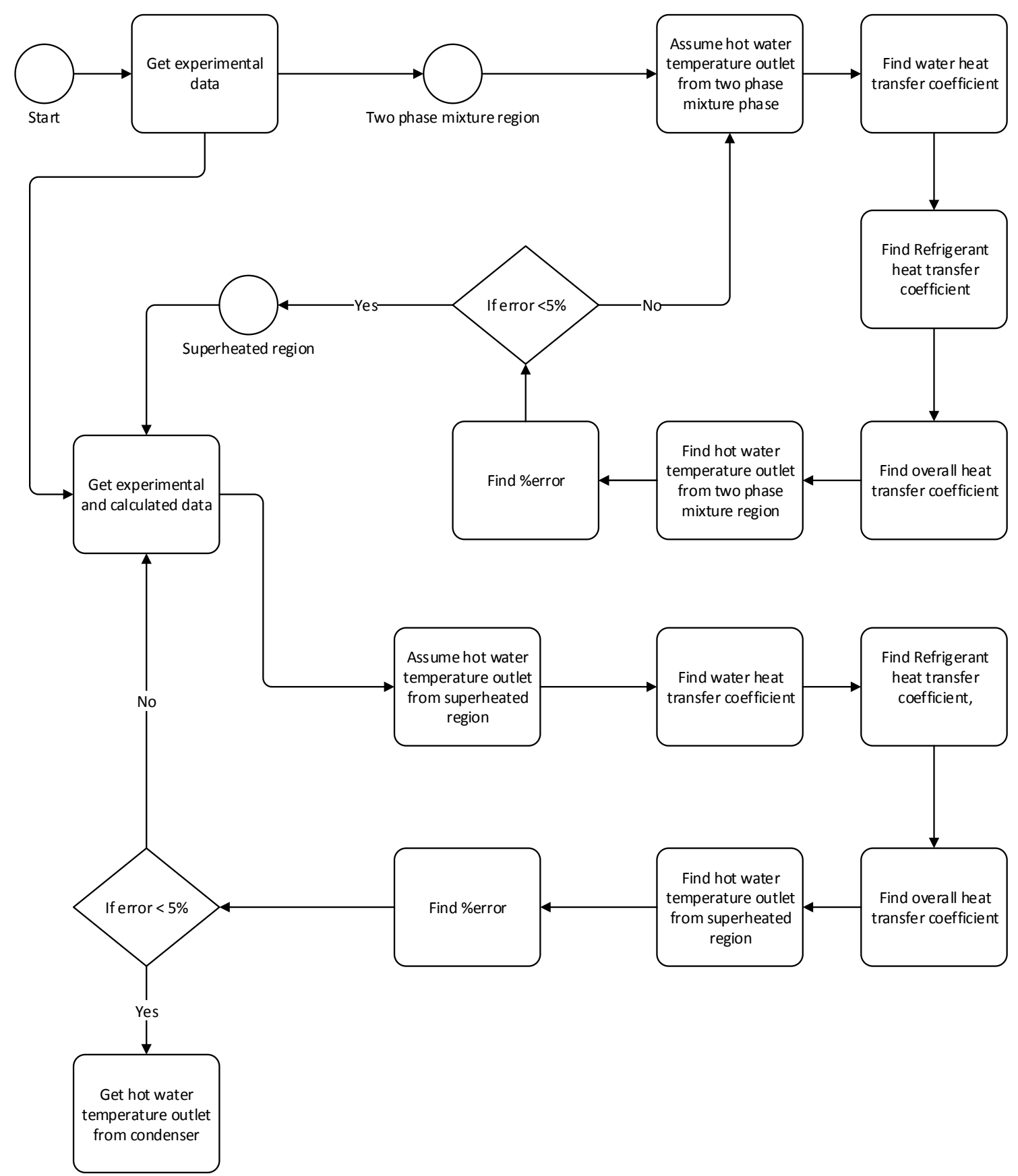

Fig. 3. The flow chart of the calculation procedure of the hot water temperature at the outlet of the condenser.

The calculation is started at the two-phase mixture region first. The heat transfer coefficient of water can be determined by Muley and Manglik relation [10] as expressed in Eq. (2). The detail description of this equation is reported in $[10,16]$.

$$
h_{w}=0.277\left(\frac{k_{w}}{d_{h}}\right) R e_{w}^{0.766} \operatorname{Pr}_{w}^{0.333}
$$

The hot water properties are functions of the average hot water temperature in the two-phase mixture region [18]. The hot water temperature at the outlet of the two-phase mixture region or $T_{w, g}$ in Fig.2 is estimated first and will be reiterated as described later. 
The R134a heat transfer coefficient in the two-phase mixture can be determined by Akers relation [10] as expressed in Eq. (3). The detail description of this equation is reported in [10, 16].

$$
h_{A K E R S}=5.03\left(\frac{k_{l}}{d_{h}}\right) R e_{e q}^{1 / 3} \operatorname{Pr}_{l}^{1 / 3}
$$

where

$$
\begin{gathered}
R e_{e q}=\frac{G\left[(1-x)+x \sqrt{\frac{\rho_{l}}{\rho_{g}}}\right] d_{h}}{\mu_{l}} \\
\operatorname{Pr}_{l}=\frac{\mu_{l} c_{p, l}}{k_{l}}
\end{gathered}
$$

The heat transfer coefficient from Eq.(3) is a local one and must be integrated to get average heat transfer coefficient in the two-phase mixture region as expressed in Eq. (4).

$$
h_{r, a v g}=\frac{1}{L_{t p}} \int_{o}^{L_{t p}} \phi h_{A K E R S} d L
$$

After getting the water and R134a heat transfer coefficient in the two-phase mixture region, the overall heat transfer coefficient in that region can be determined by Eq. (5).

$$
\frac{1}{U}=\frac{1}{h_{r}}+\frac{s}{k_{p}}+\frac{1}{h_{w}}
$$

The second term of the right side of the Eq. (5) approaches zero because of the third assumption. The hot water temperature at the outlet of the condenser can be determined by Eq.6 [19, 20].

$$
T_{w, g}=T_{w, i}+\left(T_{r, c}-T_{w, i}\right)\left(1-\exp \left(-\frac{U_{t p} A_{t p}}{\dot{m}_{w} c_{p, w}}\right)\right)
$$

The iteration method is applied to update the value of the hot water temperature at the outlet of the twophase mixture region as shown in Fig. 3.

In the superheated vapor region, the hot water temperature at the outlet of the two-phase mixture region is used as the temperature at the inlet of the superheated vapor region. The water heat transfer coefficient can also be determined by Muley and Manglik relation as expressed in Eq. 3. The R134a heat transfer coefficient can be determined by the conclusion of Webb relation [13] as expressed in Eq. (7) and the detail description of this equation is reported in $[10,16]$.

$$
h_{r, s p}=1.09 h_{r, t p}
$$

The overall heat transfer coefficient can also be determined by Eq. (5) and the hot water temperature at the outlet of the condenser can be determined by Eq. (8).

$$
T_{w, o}=T_{w, g}-\left(T_{w, g}-T_{r, i}\right)\left(\frac{1-\exp (D)}{\frac{\dot{m}_{w} c_{p, w}}{\dot{m}_{r} c_{p, r}}-\exp (D)}\right)
$$


where

$$
D=U_{t p} A_{t p}\left(\frac{1}{\dot{m}_{w} c_{p, w}}-\frac{1}{\dot{m}_{r} c_{p, r}}\right)
$$

The iteration method is applied in the similar manner to that in the two-phase mixture region in order to obtain the hot water temperature at the outlet of the condenser.

The total heat transfer of the condenser is determined by the summation of the heat transfer in the two-phase mixture region and that in the superheated vapor region as expressed in Eq. (9)

$$
\dot{Q}_{H P}=\dot{Q}_{H P, t p}+\dot{Q}_{H P, s p}
$$

where

$$
\begin{gathered}
\dot{Q}_{H P, t p}=U_{t p} A_{t p}\left(\frac{T_{w, g}-T_{w, i}}{\ln \left(\frac{T_{r, c}-T_{w, i}}{T_{r, c}-T_{w, g}}\right)}\right) \\
\dot{Q}_{H P, s p}=U_{s p} A_{s p}\left(\frac{\left(T_{r, c}-T_{w, o}\right)-\left(T_{r, c}-T_{w, g}\right)}{\ln \left(\frac{T_{r, c}-T_{w, i}}{T_{r, c}-T_{w, g}}\right)}\right)
\end{gathered}
$$

\section{Results and Discussion}

The variation of the hot water temperatures or $\mathrm{T}_{\mathrm{w}, \mathrm{o}}$ with time is depicted in Fig. 4. The hot water temperatures continuously increase with time. The non-linear behavior of $T_{\mathrm{w}, \mathrm{o}}$ is observed at the beginning of test period, namely the start-up period. It is noticed that the duration of the start-up periods in all hot water flow rates are less than 2 minutes. By comparing between different hot water flow rates, this start-up period of the lower hot water flow rate is shorter than that in case of the higher hot water flow rate. After the start-up period to the end of the test period, the linear behavior of $T_{w, o}$ is observed. The relative error between $\mathrm{T}_{\mathrm{w} . \mathrm{o}}$ obtained from the experiment and the model is large as much as 30 percent during the startup period. However, after the start-up period, the relative error reduces to less than 2 percent.

The variation of the condensation heat with time is depicted in Fig. 5. The condensation heat for all flow rates rapidly increases during the start-up period and gradually increases with time thereafter. The discrepancy between $T_{\mathrm{w}, \mathrm{o}}$ and $\mathrm{T}_{\mathrm{w}, \mathrm{i}}$ reflects the magnitude of the condensation heat, resulting in this rapid growth. By comparing between different hot water flow rates, the condensation heat at the higher hot water flow rate increases at the higher rate. In all three hot water flow rates, the value of the condensation heat after the start-up period is between 9 to $10 \mathrm{~kW}$. The results obtained from the experiment and the model are qualitatively similar. In the start-up period, the result obtained from the model is higher than the experimental one. Thereafter, the experimental result is higher due to the absence of the subcooled liquid region in the mathematical model. The relative error between the condensation heat obtained from the experiment and the model is above 100 percent during the start-up period, and it decreases to less than 4 percent at the end of the test period. 

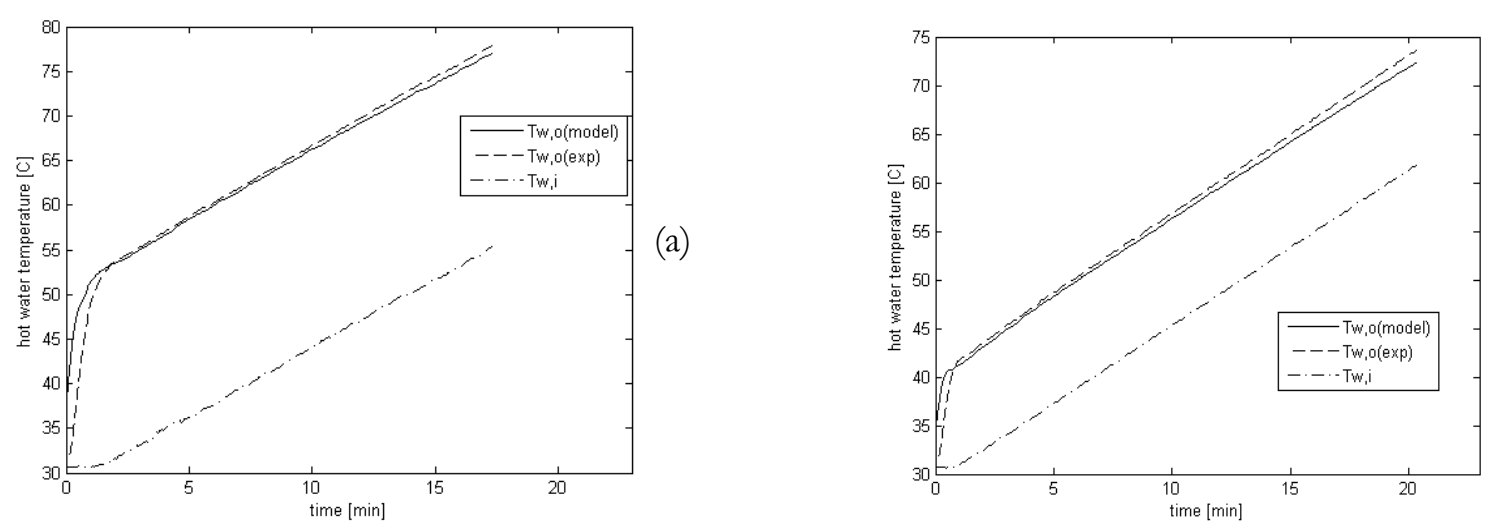

(b)

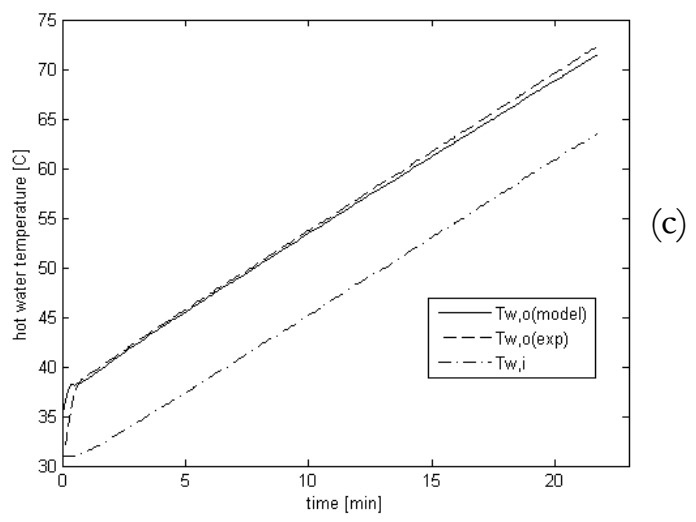

Fig. 4. The variation of the hot water temperatures with time at hot water flow rates of (a) 6 litre/min (b) 12 litre/min (c) 16 litre/min.
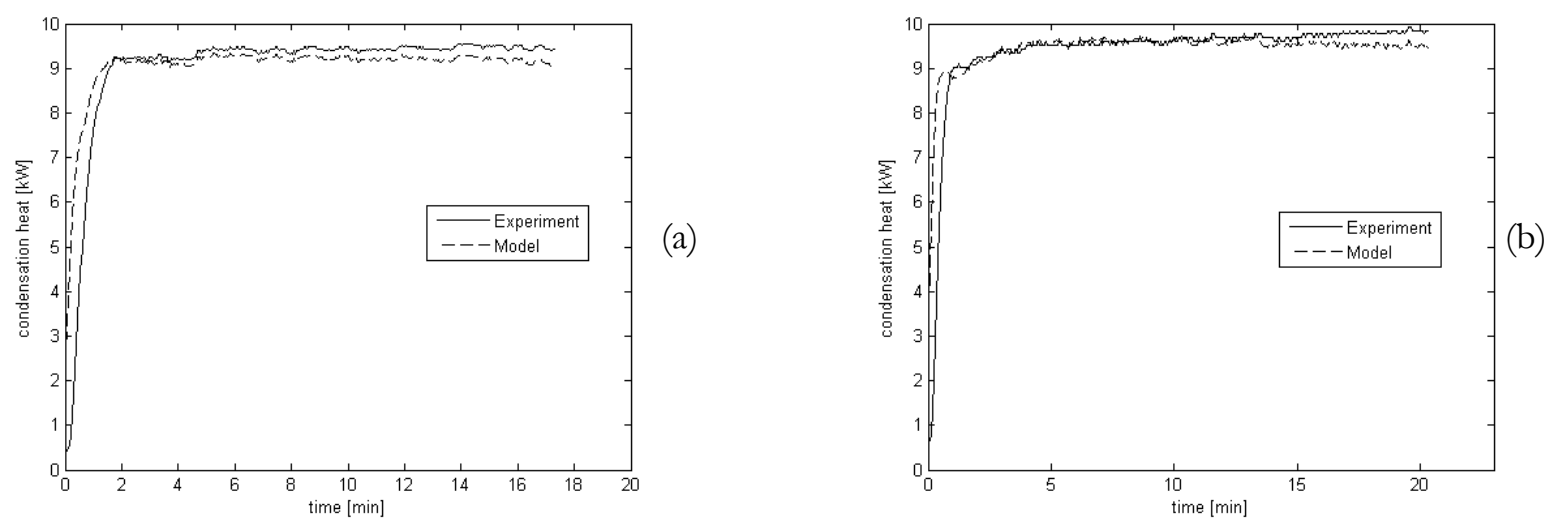


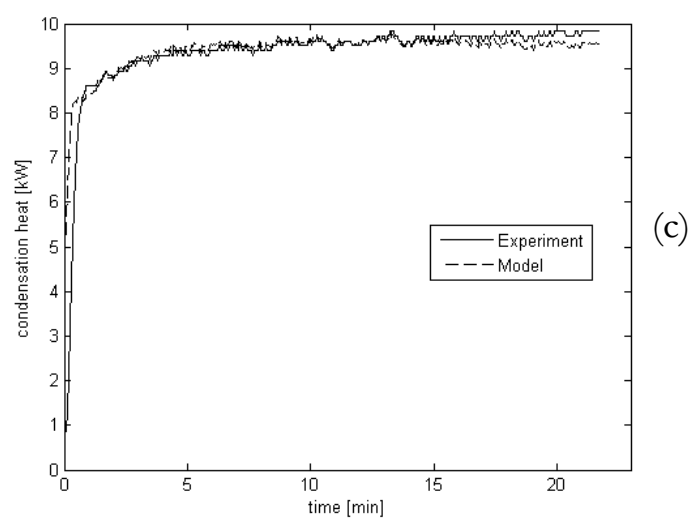

Fig. 5. The variation of the condensation heats with time at hot water flow rates of (a) 6 litre/min (b) 12 litre/min (c) 16 litre/min.

Based on the model prediction, the total heat condensation and its composition, i.e., the heat condensation in the two-phase and the superheated regions, are depicted in Fig. 6. According to the heat transfer coefficients calculated from Eqs. (2) to (7), by neglecting the heat transfer within the start-up period, the value of the water heat transfer coefficient is approximately 4,200 to $11,500 \mathrm{~W} / \mathrm{m}^{2} \mathrm{~K}$. On the other hand, the values of the R134a heat transfer coefficient is approximately 1,200 to $1,500 \mathrm{~W} / \mathrm{m}^{2} \mathrm{~K}$. As a result from Eq. (5), the value of the overall heat transfer coefficient varies from 1,000 to $1,300 \mathrm{~W} / \mathrm{m}^{2} \mathrm{~K}$. Thus, the heat transfer mechanism within the condenser is dominated by the R134a side in both of the two-phase and the superheated regions. From Fig. 6, the heat transfers in the two-phase mixture region rapidly increases in the start-up period and decreases with time later whereas the condensation heat in the superheated vapor region continuously increases with time. The condensation heat in the two-phase mixture region is approximately 70 to 75 percent of the total condensation heat. The reason is that the heat transfer area in the two-phase mixture regions is larger than that in the superheated one.
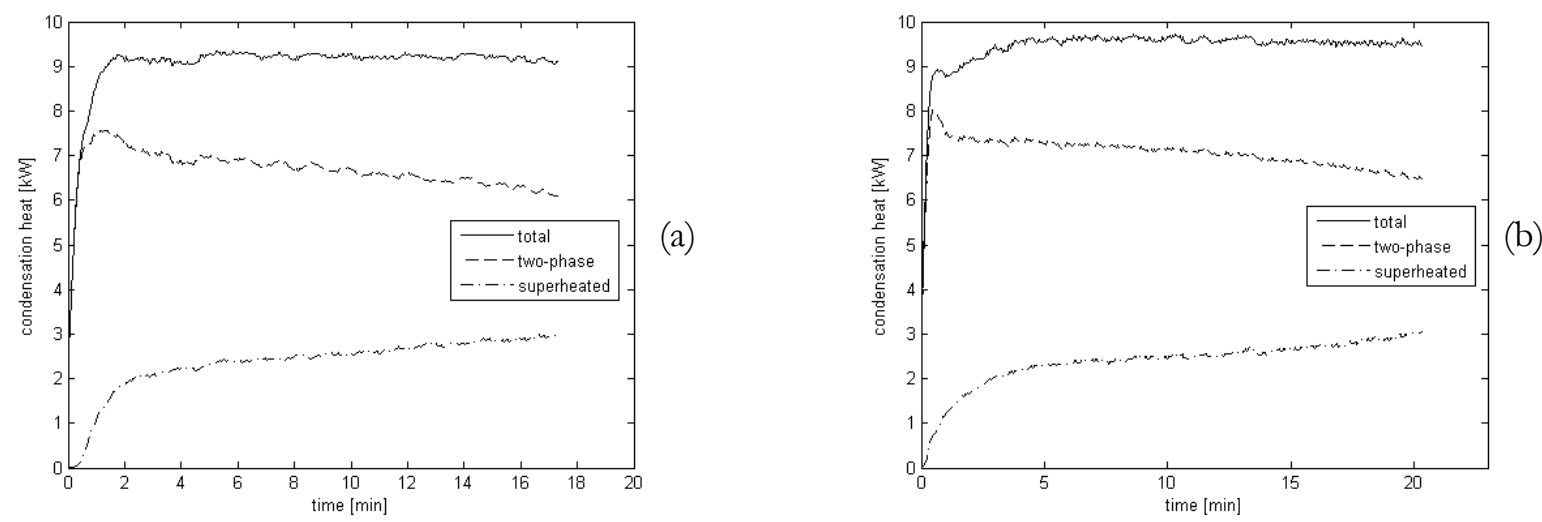


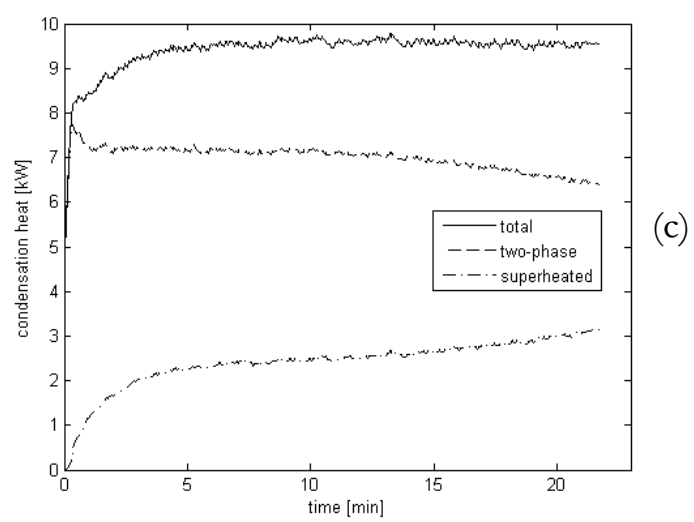

Fig. 6. The variation of the two-phase, superheated and total condensation heats with time from the model prediction at hot water flow rates of (a) 6 litre/min (b) 12 litre/min (c) 16 litre $/ \mathrm{min}$.

The variation of the measured compressor power of the high-temperature heat pump cycle at different hot water flow rates is depicted in Fig. 7. At all hot water flow rates, the compressor power of the heat pump cycle increase with time. By comparing different hot water flow rates, the compressor power at the high hot water flow rate is lower than that at the low hot water one because of the higher condensation heat. Based on the 6-litre/min hot water flow rate, the heat-pump compressor power at 12 and $16 \mathrm{litre} / \mathrm{min}$ decreases by approximately 12 and 15 percent, respectively.

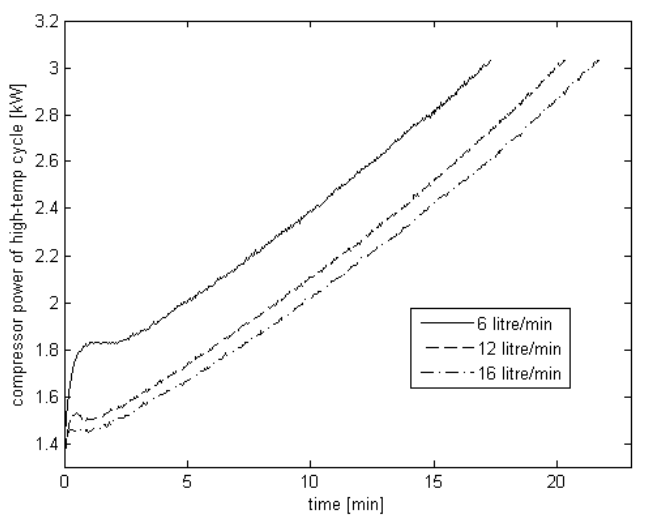

Fig. 7. The variation of the compressor power of the high-temperature heat pump cycle at different hot water flow rates.

The variation of the measured COP of the high-temperature heat pump cycle at different hot water flow rates is depicted in Fig. 8. Note that the COP of the heat pump cycle is defined as the total condensation heat over the heat-pump compressor power. At all hot water flow rates, the COP of the heat pump cycle increases at the start-up period and then decreases toward the end of the test period. By comparing different hot water flow rates, the COP at the high hot water flow rate is higher than that at the low hot water one. Based on the 6-litre/min hot water flow rate, the heat-pump COP beyond the start-up period at 12 and 16 litre/min increases by approximately 15 and 20 percent, respectively. This result indicates the higher efficiency of the heat pump when operated at the higher hot water flow rate. 


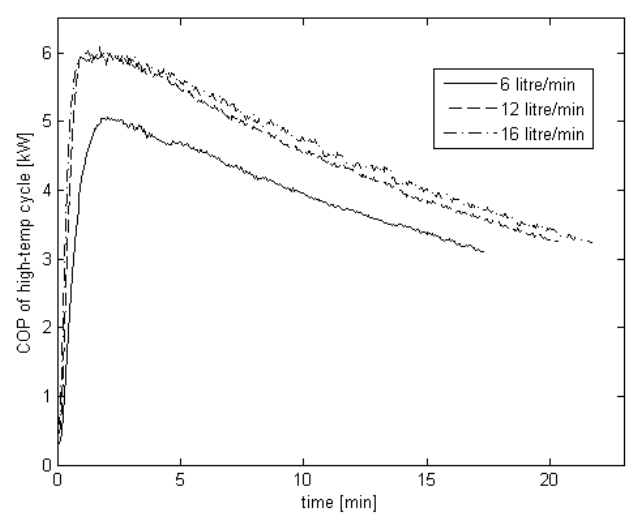

Fig. 8. The variation of the COP of the high-temperature heat pump cycle at different hot water flow rates.

\section{Conclusion}

The effect of the transient heat transfer of a condenser of the cascade heat pump performance has been presented in this study. The comparison between the mathematical model and the experimental result has been made. The both results indicates that the hot water temperature continuously increases with time whereas the condensation heat rapidly increases during the start-up period and gradually increases with time. The relative error between the results obtained from the experiment and the model is relatively large during the start-up period, but it will decrease toward the end of the test period. Based on the model prediction, the heat transfer mechanism within the condenser is dominated by the R134a side in both of the two-phase and the superheated regions. 70 to 75 percent of the total condensation heat comes from the condensation heat in the two-phase mixture region. According to the experimental result, the measured compressor power of the heat pump decreases with increasing hot water flow rate. On the other hand, the measured COP increases with increasing hot water flow rate, resulting in the higher efficiency of the heat pump.

\section{Nomenclature}

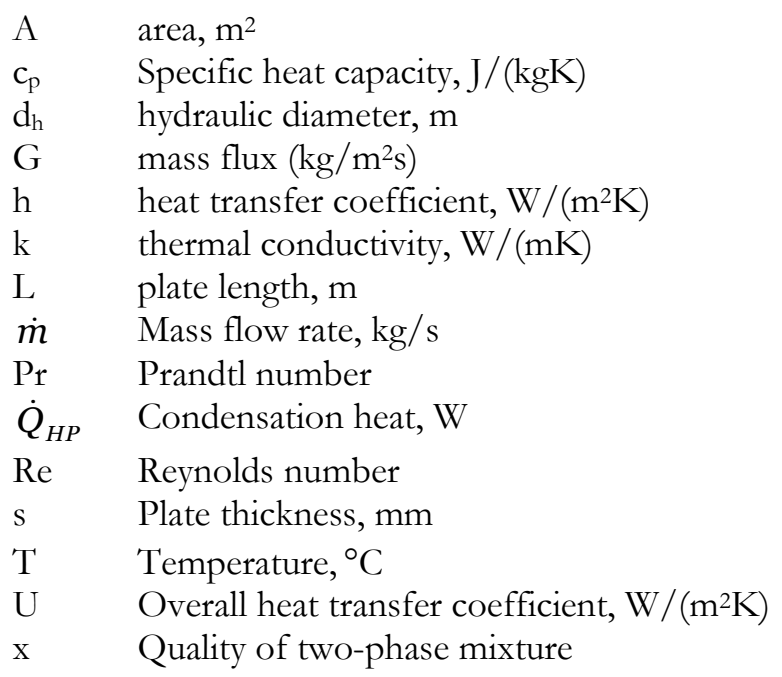

\section{Greek symbols}

$\begin{array}{ll}\mu & \text { Viscosity, } \mathrm{Ns} / \mathrm{m}^{\mathrm{s}} \\ \rho & \text { Density, } \mathrm{Kg} / \mathrm{m}^{2} \\ \phi & \text { Enlargement factor }\end{array}$

\section{Subscripts}




$\begin{array}{ll}\text { avg } & \text { average } \\ \mathrm{g} & \text { saturated vapor } \\ \mathrm{w} & \text { hot water } \\ \mathrm{i} & \text { inlet } \\ \mathrm{l} & \text { liquid } \\ \mathrm{O} & \text { outlet } \\ \mathrm{p} & \text { plate heat exchanger } \\ \mathrm{r} & \text { refrigerant R134a } \\ \mathrm{sp} & \text { superheated vapor } \\ \mathrm{tp} & \text { two-phase mixture }\end{array}$

\section{Acknowledgement}

The authors would like to thanks faculty of Engineering, Chulalongkorn University for their supporting financial and laboratory.

\section{References}

[1] S. Bhattacharyya, S. Mukhopadhyay, A. Kumar, R. K. Khurana, and J. Sarkar, "Optimization of a $\mathrm{CO}_{2}-\mathrm{C}_{3} \mathrm{H}_{8}$ cascade system for regrigeration and heating," International of Refrigeration, vol. 28, no. 8, pp.1284-1292, 2005.

[2] S. Bhattacharyya, A. Garai, and J. Sarkar, "Thermodynamic analysis and optimization of a novel $\mathrm{N}_{2} \mathrm{O}-$ $\mathrm{CO}_{2}$ Cascade system for refrigeration and heating," International Journal of Refrigeration, vol. 32, no. 5, pp. 1077-1084, 2009.

[3] J. A. Dopazo, J. Fernandez-Seara, J. Sieres, and F. J. Uhia, "Theoretical analysis of $\mathrm{CO}_{2}-\mathrm{NH}_{3}$ cascade refrigeration system for cooling applications at low temperature," Applied Thermal Engineerung, vol. 29, no. 8, pp. 1577-1583, 2009.

[4] D. Colorado, J. A. Hernandez, and W. Rivera, "Comparative study of a cascade cycle for simultaneous refrigeration and heating operating with ammonia, $\mathrm{R} 134 \mathrm{a}$, butane, propane and $\mathrm{CO}_{2}$ as working fluids," International Journal of Sustainable Energy, vol. 31, no. 6, pp. 365-381, 2011

[5] D. H. Kim, H. S. Park, and M. S. Kim, "Optimal temperature between high and low stage cycles for R134a/R410A cascade heat pump based water heater system," Experimental Thermal and Fluid Science, vol. 47, pp. 172-179, 2013.

[6] H. W. Jung, W. Kang, W. J. Yoon, and Y. Kim, "Performance comparison between a single-state and a cascade multifunctional heat pump for both air heating and hot water supply," International Journal of Refrigeration, vol. 36, no. 5, pp. 1431-1441, 2013.

[7] T. Lee, C. H. Liu, and T. W. Chen, "Thermodynamics analysis of optimal condensing temperature of cascade-condenser in $\mathrm{CO}_{2} / \mathrm{NH}_{3}$ cascade refrigeration systems," International Journal of Refrigeration, vol. 29, no. 7, pp. 1100-1108, 2006.

[8] H. Park, D. H. Kim, and M. S. Kim, "Performance investigation of a cascade heat pump water heating system with a quasi steady-state analysis," Energy, vol. 63, pp. 283-294, 2003.

[9] A. Jokar, H. M. Hosni, and J. S. Eckels, "Dimensional analysis on the evaporation and condensation of refrigerant R-134a in minichannel plat heat exchangers," Applied Thermal Engineering, vol. 26, no. 17, pp. 2287-2300, 2006.

[10] A. G. Longo, "Refrigerant R134a condensation heat transfer and pressure drop inside a small brazed plate heat exchanger," International Journal of Refrigeration, vol. 31, no. 5, pp. 780-789, 2008.

[11] W. Nusselt, The Basic Law of Heat Transfer. 1916.

[12] P. F. Incropera, D. P. Dewitt, T. L. Bergman, and A. S. Lavine, Introduction to Heat Transfer, 5th ed. Asia: John Wiley \& Son, 2007.

[13] R. L. Webb, "Convective condensation of superheated vapor," ASME Journal Heat Transfer, vol. 120, no. 2, pp. 418-421, 1998.

[14] A. G. Longo, "The effect of vapour super-heating on hydrocarbon refrigerant condensation inside brazed plate heat exchanger," Experimental Thermal and Fluid Science, vol. 35, no. 6, pp. 978-985, 2011. 
[15] S. Mancin, D. D. Col, and L. Rossetto, "Condensation of superheated vapour of R410C and R407C inside plate heat exchangers: Experimental results and simulation procedure," International Journal of Refrigeration, vol. 35, no. 7, pp. 2003-2013, 2012.

[16] V. Grabenstein and S. Kabelac, "Experimental and theoretical analysis of the local condensation heat transfer in a plate heat exchanger," Journal of Physics: Conference Series, vol. 395, no. 1, p. 012169, 2012.

[17] Y. C. Yang, H. Y. Lin, and C. F. Lin, "Effect of flow direction for heat transfer performance of refrigerant R-410A evaporation in plate heat exchanger," Heat Tranfer Engineering, vol. 34, no. 13, pp. 1133-1139, 2013.

[18] C. Borgnakke and R. E. Sonntag, Fundamentals of Thermodynamics, 7th ed. Asia: John Wiley \& Son, 2008.

[19] W. F. Stoecker, Design of Thermal System, 3rd ed. USA: McGraw-Hill, 1989.

[20] W. S. Janna, Design of Fluid Thermal System, 1st ed. USA: PWS-KENT, 1993. 